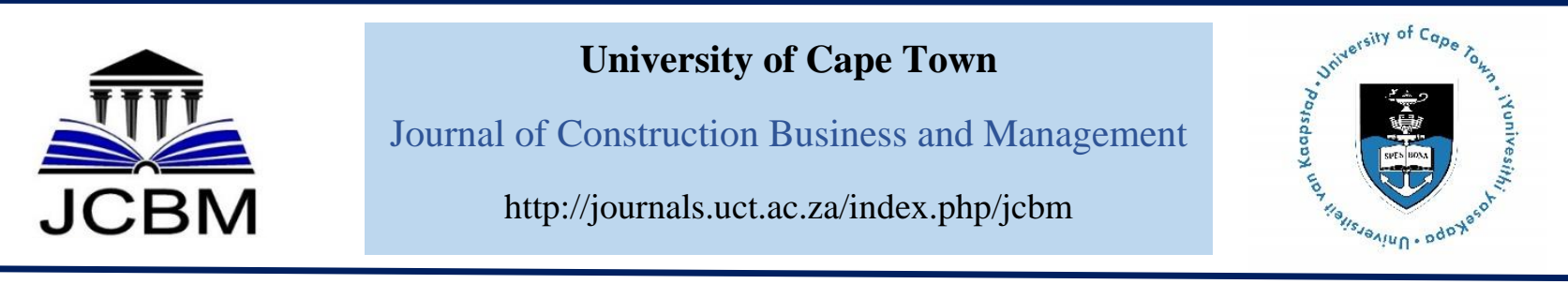

\title{
The Management of Theft and Vandalism on Construction Jobsites in the Southern Region of Malawi
}

\author{
W. Simukonda ${ }^{1}$ and N. Kamwela ${ }^{2}$ \\ ${ }^{1 \& 2}$ Department of Land Economy and Quantity Surveying, Malawi University of Business and Applied Sciences
}

Received 15 April 2021; received in revised form 18 July 2021 and 28 August 2021; accepted 30 August 2021.

https://doi.org/10.15641/jcbm.5.1.1072

\begin{abstract}
The phenomenon of theft and vandalism on construction job sites in Sub-Saharan Africa (SSA) has not been fully explored to guarantee the implementation of evidence-based security management practices (SMPs) to minimise losses and improve projects' profitability margins. This study investigated the management of theft and vandalism by large contractors in the Southern Region of Malawi to identify implementation issues that need improvement. A quantitative approach using an empirical survey-based questionnaire was adopted. 44 SMPs identified from the literature review were tested by data collected from a sample survey of 40 large contractors in the Southern Region of Malawi. The descriptive statistical method of mean score ranking was used to analyse the data through IBM Statistical Package of Social Sciences (SPSS) version 20.0. Among the five-point Likert scale agreement measurements used, 11 SMPs were found to be "always used", 12 SMPs "often used", 15 SMPs "sometimes used", and six SMPs "rarely used". Overall, the top three highly ranked SMPs (in descending order) were inventorying construction materials, tools and equipment, termination of employment for offenders, and reporting theft and vandalism to enforcement agencies. Contrariwise, the use of closed-circuit television (CCTV), alarm systems and access control systems (ACS) was the least ranked SMPs. The contractors' management improvements for theft and vandalism would need to focus on implementing proactive anti-theft and anti-vandalism SMPs whose choice should be informed by comprehensive Jobsite security risk assessment. Dissemination of the results may help contractors understand their security management strategies and implement practical solutions for curbing theft and vandalism on job sites to minimise its endemic effect on contractors' financial performance.
\end{abstract}

Keywords: Theft and Vandalism; Security management practices; Likert scale; Malawi.

\section{Introduction}

Over the recent two decades, incidents of theft and vandalism in the construction industry have evolved from conventional theft and vandalism of materials and fixtures to sophisticated crimes targeting expensive construction assets. The consequences of theft and vandalism are direct and indirect costs incurred by contractors. Farinloye et al. (2012) reported that contractors lose huge sums of money through theft and vandalism each year. Direct costs comprise replacement costs and a residual value of the stolen or damaged item (Ablordeppey et al., 2020). Conversely, indirect costs consist of productivity and administrative losses, disruption in business operations, lost contracts and penalty clauses (Sakurai et al., 2008). Financial losses resulting from theft and vandalism have profound negative impacts on projects' profitability margins (Berg and Hinze, 2005). In order to minimise costs of theft and vandalism and improve profitability, and sustained business growth and stability, contractors are challenged to implement appropriate security management practices (SMPs). Several authors have recommended measures for curbing theft and vandalism on job sites. Some of the predominant ones include inventorying construction assets, marking of plant with indelible identifications, use of secure storage areas and

${ }^{1}$ Corresponding Author.

Email address: wsimukonda@poly.ac.mw

C2021The Authors. Published by UCT Libraries. This is an open access article under the CC BY 4.0 license.

https://creativecommons.org/licenses/by/4.0/ 
perimeter fencing (Ablordeppey, 2020: 38-39; Edike and Babatunde, 2017). However, their effectiveness has been questioned as more incidents of theft and vandalism continue to occur on job sites. Other authors have mourned the underutilisation of appropriate measures such as closed-circuit television (CCTV), alarm systems and background checks on applicants' records (Edike and Babatunde, 2017). This has been partly attributed to high capital cost (Ablordeppey et al., 2020) associated with their implementation and, therefore, common among small and medium-sized contractors. However, for large contractors, the cost-benefit analysis for adopting these SMPs is sufficiently compelling. Unfortunately, these SMPs continue to be neglected, as recently observed by Ablordeppey et al. (2020) and large contractors, according to Farinloye et al. (2012), continue to experience huge losses from theft and vandalism.

Therefore, crime prevention has become a major concern for players in the construction industry as losses from theft and vandalism can greatly affect the profitability of contractors. Considering the industry's economic contribution to the national economies, effective security strategies must be explored and implemented to minimise losses to contractors. Further, theft and vandalism remain insufficiently researched phenomena within the construction management discipline in Africa, specifically, Sub-Saharan Africa (SSA). Several studies, including that of Edike \& Babatunde (2017), Farinloye et al. (2013) and Ablordeppey et al. (2020), were conducted in Nigeria and Ghana. These studies may not adequately portray the experiences of SSA countries to the phenomenon. The lack of practical experience of contractors SMPs could be the missing link in implementing evidence-based strategies to make construction job sites less attractive to thieves and vandals. Further, not much is read into the SMPs used on construction job sites due to the previous studies probing few SMPs. The current study conducted a thorough literature review and compiled a long list of successful SMPs for preventing crime on construction job sites, which was then probed. Hence, the purpose of this study was an assessment of SMPs implemented by large contractors in curbing crimes on construction job sites in the Southern region of Malawi.

The following section defines the terms theft and vandalism and the kinds of crime incidents and criminals. Various causes of theft and vandalism, including locations of job sites, are discussed in section 3, while sections 4 and 5 highlight the cost of theft and vandalism and symmetrical measures for their prevention on job sites. Section 6 presents methods used to collect and analyse the data on the assessment of SMPs implemented by contractors. Section 7 discusses the findings related to the data collected and the literature reviewed, while section 8 provides major practical and theoretical implications of the study.

\section{An overview of construction theft and vandalism}

The People's Law Dictionary (1981) defines theft as "a generic term for all crimes in which a person intentionally and fraudulently takes personal property of another without permission or consent and with the intent to convert it to the takers' use (including potential sale)."
Construction job sites are naturally at high risk of victimisation due to the valuable assets found on them. Such items include large excavators, loaders, vibrator rollers, dumpers, generators, pumps, drillers, breakers, shutters and scaffolds (Gwynn et al., 2005). According to Boba and Santos (2006), theft of high-value assets such as construction plant results in loss of profits for contractors and sordid gain and filthy lucre for criminals. Conversely, Farinloye et al. (2012) describes vandalism as a crime of destroying or damaging something or property deliberately and for no good reason. Though it does not result in massive losses for contractors, Berg and Hinze (2005) states that vandalism is a nuisance that must be avoided. Vandalism manifests in the form of destruction of in-place materials, graffiti, broken glass and damage to construction plants (Farinloye et al., 2012). Taken together, theft and vandalism ought to be critical facets of commercial construction projects which must be given attention.

Boba and Santos (2006) categorise perpetrators of theft and vandalism into amateur opportunists, insiders and professional thieves. The authors describe amateur opportunists as people who dwell or travel within the vicinity of the Jobsite and who usually steal small items circumstantially. However, such burglars do not pose a higher security risk than insiders if job sites are well protected. Instead, insiders - contractors' employees, pose a higher security risk because they know the job site's security procedures. Even more risky is theft by professional thieves, who use sophisticated means to steal high-value construction assets (Ablordeppey et al., 2020).

\section{Factors contributing to theft and vandalism}

Understanding the factors that predominantly cause theft and vandalism on construction job sites is critical for selecting effective security measures for curbing the crimes. The following section discusses several factors that emerge as contributing to the vulnerability of job sites to theft and vandalism.

\subsection{Location and accessibility}

Construction job sites locations and accessibility are important risk factors. Warne (2016) found that crime increases when working in or around cities and big towns. Similarly, Sakurai et al. (2008) observed consistently higher theft and vandalism rates in central business districts (CBDs), reporting $40 \%$ and $25 \%$ each for job sites located in inner-city suburbs and outer suburbs respectively. Generally, cities and towns are characterised by high population and unemployment rates which may instigate theft and vandalism on job sites. Iwuagwu (2014) affirmed a direct relationship between locations with a high population and unemployment rates with the crime rate. Sakurai et al. (2008) and Boba and Santos (2006) state that construction job sites, greater visibility and accessibility further compounds the problem, especially for job sites with inferior security features.

\subsection{Time and days}

Construction job sites theft and vandalism are predominant on specific days and times. A study by Sakurai et al. (2008) discovered that $67 \%$ of theft occurs 
during weekdays and $33 \%$, with more incidents of vandalism during weekends. This is corroborated by Smith and Walmsley (1999), who discovered that stolen equipment was reported seen on Friday and missing the following Monday. Further, Sakurai et al. (2008) showed that theft and vandalism mainly occur in the evening and at night, with few pockets of incidents in the morning and evening. These observations could be attributed to fewer workers and guardianship available at the Jobsite at the mentioned timestamp. Berg and Hinze (2005) characterises a construction Jobsite as a 'ghost town' after hours and, as such, a soft target by criminals.

\subsection{High cost and shortage of construction items}

The high cost of construction assets encourages theft and vandalism on construction job sites and increases the risk of victimisation by professional thieves. Similarly, a shortage of construction materials such as cement, wood and steel in local markets instigates burglary. Shortage of materials is attributed to production and logistical challenges inherent in the supply chain, for the importdependent products and inability to meet local demand by local suppliers, for locally produced materials (Rahman et al., 2017). High demand for construction materials in the local markets may create an appetite for theft of cash value materials, which according to Ablordeppey et al. (2020), may be sold to readily available buyers in the steal-to-order business.

\subsection{Inferior security measures}

According to Sakurai et al. (2008), hardly any optimal security measures are used to secure construction job sites. If any, contractors generally employ unsophisticated and relatively easy to breach measures. Several thefts and vandalism incidents have occurred on job sites, with some of the SMPs, such as fencing and storage areas, duly in place (Berg and Hinze, 2005).

\subsection{Negligence}

Among the contractors' negligent tendencies include delivering materials onsite before their installation time, the tendency of not checking tools in and out daily and non-reporting of theft and vandalism incidents to police agencies (Boba \& Santos, 2006). Such proclivities give employees the impression that their employer is not serious about the security of the job site. Less attention given to security issues breeds rationalisation (Berg and Hinze 2005), resulting in more thefts and losses for the contractor.

\subsection{Labour practices}

Crime on construction job sites may be a sign of reprisals as a result of unfair labour practices. Unfair termination of employees accounts for many incidents of crime on job sites (Berg and Hinze 2005; Farinloye et al., 2012). The authors suggest reinforcement of security on construction job sites, especially in the moments leading to and after a difficult termination or dismissal.

\section{Cost of construction theft and vandalism}

The losses due to construction job sites theft and vandalism run into millions of dollars. In Europe, the value of plant purloined annually is as high as $\$ 9$ billion with around \$144 million, \$90 million and \$38 million in France, Netherlands and Belgium, respectively (Gwynn et al., 2005). In the UK and the US, the annual loss due to equipment theft accounts for $£ 500$ million (Allianz, 2018) and $\$ 1$ billion (Sharma \& Bausman, 2009), respectively. The US's mean dollar losses resulting from theft and vandalism of construction assets were $\$ 1,388 / 1$ million of work performed (Berg \& Hinze, 2005) and \$100,000 (Montealegre, 2003), respectively. According to Big Box (2018), construction job sites theft account for the loss of R1 billion in the South African construction industry. The direct costs of theft and vandalism include replacement cost (new-for-old) and residual value (depreciated) and indirect costs such as productivity loss, hire replacement cost, increased premium insurance and social costs (Sakurai et al., 2008: 20). However, the figures given above could be a tip of an iceberg as the fuller and accurate loss associated with theft and vandalism is unknown owing to the lack of systematic methods of estimating the losses (Berg \& Hinze, 2005:). Berg and Hinze (2005) summarises the consequential impact of theft and vandalism as having "a direct impact on the success of a project and diminish the potential profitability of the project" under construction. Addressing theft and vandalism management challenges could therefore protect millions of dollars and improve contractors' financial performance.

\section{Construction job sites security measures 5.1 Perimeter fencing}

Perimeter fencing is temporary structures installed to protect the peripheral of the construction job site and used as a delaying tactic measure in crime prevention (Edike and Babatunde, 2017). Several forms of perimeter fencing exist, including solid flat-sided hoardings and mesh wire fencing (BSIA, 2012; Farinloye et al., 2013). Perimeter fences should be designed to prevent climbing by installing ant-climb features such as spikes or barbed wire and eliminate any form of hand and footholds (BSIA, 2012). The type of fence to be employed on a construction job site should depend on the nature of the perceived threat in the area. Where possible, it is recommended to construct permanent fencing, which usually stands on a concrete foundation and prevent burrowing (BSIA, 2012). Overall, fencing is an effective security measure common among contractors (Ablordeppey et al., 2020).

\subsection{Entrances and exits}

Minimising the number and locking of the gates optimise accessibility control at the job sites (BSIA, 2012; Ablordeppey et al., 2020). The authors state that entrance and exit should be controlled by guards or electronic entrance systems. Gates must be designed to avoid being easily breached by using locks, protection plates and padlocks (BSIA, 2012). Where possible, Farinloye et al. (2012) recommends off-site parking of workers' private vehicles to minimise vehicular numbers onsite.

\subsection{Secure storage}

Construction job sites keep high-value assets that need proper storage. For equipment, BSIA (2012) recommends designating a secure parking lot with controlled access. Workers should ensure that all assets are returned, and 
keys for vehicles are properly secured. The use of steel vaults with shielded padlocks is recommended for the storage of tools. Locked containers or site huts can be used as storage areas. However, extra security features such as steel doors, locks and key controls could be incorporated to make storage areas sturdier (Edike and Babatunde, 2017).

\subsection{Security lighting}

Lighting is used as a deterrent mechanism by illuminating the whole construction Jobsite or specific areas such as gates or parked equipment locations. It was a highly rated security measure for protecting construction assets (Ablordeppey et al., 2020) and a frequently used measure on job sites (Sharma and Bausman, 2009). However, it is recommended that wires and cables for the lighting network should be barely exposed and switches only accessible to authorised personnel (BSIA, 2012). Photoelectric cells may be used to protect the lighting from tampering or vandalism by intruders (BSIA, 2012). At the minimum, the authors advise directing the lighting inwards to reveal intruders either directly or by silhouette.

\subsection{Technical systems}

Technical systems comprise CCTV, access control systems (ACS) and alarm systems (BSIA, 2012). They use cameras, multiplexers, monitors, recorders or intrusion detection systems (Edike and Babatunde, 2017: $35)$ to provide deterrent and mitigation effects to security risks inherent on construction job sites (BSIA, 2012). However, recent studies emanating from countries in Western Africa, such as Nigeria and Ghana, indicate that CCTV and alarm systems are the least used (Edike and Babatunde, 2017) and ineffective measures (Ablordeppey et al., 2020) for preventing crime on job sites. The observation is attributed to the high capital outlay associated with the technology. Additionally, their usage is particularly low among small and medium-size contractors due to low-risk projects such firms executed (Edike and Babatunde, 2017). However, technical systems are viable for high-risk projects (Edike and Babatunde, 2017), where the cost-benefit ratio is sufficiently compelling for their deployment (BSIA, 2012).

\subsection{Guarding services}

The use of guard force was ranked 1st and 2nd as the most frequently used and efficient on job sites of Ghanaian contractors, respectively (Ablordeppey et al., 2020). Depending on the perceived security risk, contractors may employ their trained guards or outsource the services of security companies. However, it is prudent to consider personnel training, qualification (Edike and Babatunde, 2017), and communication systems for greater liaison with police agencies (BSIA, 2012), especially when employing their guards. Overall, afterhours guards are common among contractors with higher annual volume turnover (Sharma and Bausman, 2009).

\subsection{Policy and processes}

Contractors ought to have a security policy to guide job sites security operations. The policy must lucidly state the obligations and responsibilities of employees (BSIA, 2012). Some of the measures and processes must include making employees responsible for assets they use, reporting theft and vandalism to police agencies, an anonymous system of reporting suspicious activities, and other legislative and administrative practices such as the procedure for hiring (pre-screening of applicants) and termination of employment, provision for crime prevention coordinator and inventory supervisor (Edike and Babatunde, 2017; Farinloye et al., 2013). Administrative processes have proved effective in mitigating crime on construction job sites (Sharma and Bausman, 2009). For example, assigning specific security-related responsibilities may promote accountability and transparency in theft and vandalism management.

Other measures for protecting high-value construction assets on job sites include marking all assets with quick visual identifications, maintaining inventory of tools and equipment, immobilising plants, not in use, providing vehicle or product identification numbers and strategic parking of equipment (Ablordeppey et al., 2020; Edike and Babatunde, 2017). A list of SMPs as reviewed from literature is provided in appendix 1 .

\section{Research Methodology}

The study was aimed at assessing the SMPs implemented by contractors in the Southern region of Malawi. A quantitative research approach using a questionnaire survey as an instrument for data collection was adopted. The rationale for this approach was that questionnaires are commonly reported to develop scales intended to measure the frequency of effective constructs such as experiences and processes (Fadiya et al., 2012; Rowley, 2014). The questionnaire instrument was compiled, piloted and amended as suggested by professional experts. Minor changes were made to the actual wording of the SMP variables to maximise communication of information in the main stage of the survey. The study targeted senior management personnel of large contractors such as directors and managers. The risk of theft and vandalism is higher on job sites of large contractors (Sakurai et al., 2008), and senior management personnel are more likely to be knowledgeable of their companies' theft and vandalism management practices (Farinloye et al., 2013).

\subsection{Research instrument}

The survey instrument was structured and comprised questions eliciting single or multiple-choice responses. Questionnaires with a combination of response options to questions are common in construction management research (Berg \& Hinze, 2005; Babatunde et al., 2018; Fadiya et al., 2012). The questionnaire was divided into two major sections. Section A sought demographic information of the respondents and the contractors' business characteristics, such as professional roles, experience, age, and size, to determine the credibility of the collected data. Section B was designed to assess how frequently particular SMPs were used to curb theft and vandalism on construction job sites. Unlike previous 
studies which had probed relatively fewer SMPs, such as seven (Ablordeppey et al., 2020), 11 (Farinloye et al., 2013), 30 (Edike \& Babatunde, 2017), this study tested 44 SMPs, compiled from a comprehensive literature review of empirical research papers (Ablordeppey et al., 2020: 30; Farinloye et al., 2013; Fadiya et al., 2012; Berg and Hinze, 2005; Edike \& Babatunde, 2017). The selection was conducted to avoid omissions or repetitions of the measures appearing in various sources.

Likert scale, one of the most popular response scales used in survey designs (Chyung et al., 2017) and general construction management research (Danku, 2020; Edike \& Babatunde, 2017; Chileshe et al., 2020), was used to capture SMPs implemented by contractors on job sites. Several Likert scale formats exist, including a five-point (Farinloye et al., 2013), a seven-point (Osei-Kyei \& Chan, 2016) and a ten-point (Babatunde et al., 2018). However, a five-point Likert scale rating is common in construction management research (Nyakala et al., 2021; Wuni et al., 2021; Fadiya et al., 2012). This is due to the reliability and validity to produce unbiased data (Chyung et al., 2017). More importantly, a five-point Likert scale was adopted to generate interval scale data that could be interpreted using descriptive statistics (Chyung et al., 2017). Additionally, to avoid cognitive effort and mis-responses due to respondents being under time pressure or less experienced in survey questionnaires, a Likert scale rating with fewer descriptors such as five was deemed necessary. A five-point Likert scale maximises the communication within the gradations of agreement scales used and allows the respondents to express their opinions succinctly (Chyung et al., 2017). However, mid-point Likert type scales are criticised for creating response tendencies, satisfying behaviours and social desirability bias (Chyung et al., 2017: 17) which compromise the quality of the data. However, response tendencies were avoided in this study by targeting senior management personnel directly involved in decision making regarding the management of theft and vandalism, thereby being unambiguously well knowledgeable on the responses to provide. As such, the respondents were invited to indicate the frequency of use of the SMPs on a five-point Likert scale where $1=$ never used, $2=$ rarely used, $3=$ sometimes used, $4=$ often used, and $5=$ always used.

\subsection{Sampling design}

The study population comprised contractors licensed by Malawi's national construction industry council (NCIC) to undertake building and civil engineering works for the financial year 2019-2020. The sampling frame was retrieved from the NCIC website and comprised 591 building and civil engineering contractors operating in the Southern region of Malawi. The purposive sampling method was used to select contractors licensed to operate in financial classes of 6,7 and 8 (See Table 1) for two reasons. First, based on their financial capacity, tiers 6,7 and 8 are deemed medium and large contractors with higher or no financial limit on contracts they tender for. According to Farinloye et al. (2012), large contractors experience huge losses due to theft and vandalism. Besides, they are involved in large construction projects where many construction assets are deployed (Fadiya et al., 2012). Further, large construction projects entail a large onsite construction workforce, putting construction job sites at a higher security risk. Second, this profile of respondents tends to have established physical offices for the administration of the questionnaires. This study's questionnaire was self-distributed to avoid very low returns associated with online or emailed questionnaire surveys. A similar approach was employed by Edike \& Babatunde (2017) on a study of crime prevention in Ogun state, Nigeria. Consequently, 98 contractors were sampled to participate in the survey.

Table 1: NCIC classification of contractors

\begin{tabular}{ccc}
\hline Class & $\begin{array}{c}\text { Building Category } \\
\text { (MWK) }\end{array}$ & $\begin{array}{c}\text { Civil Category } \\
\text { (MWK) }\end{array}$ \\
\hline 1 & $10.0 \mathrm{M}$ & $10.0 \mathrm{M}$ \\
2 & $20.0 \mathrm{M}$ & $20.0 \mathrm{M}$ \\
3 & $50.0 \mathrm{M}$ & $50.0 \mathrm{M}$ \\
4 & $100.0 \mathrm{M}$ & $100.0 \mathrm{M}$ \\
5 & $200.0 \mathrm{M}$ & $200.0 \mathrm{M}$ \\
6 & $500.0 \mathrm{M}$ & $500.0 \mathrm{M}$ \\
7 & 1.0 Billion & 1.0 Billion \\
8 & Unlimited & Unlimited \\
\hline
\end{tabular}

Note: $M=$ Million; $M W K=$ Malawi Kwacha.

(Source: NCIC, 2019)

\subsection{Data Analysis}

The study adopted the data analysis techniques as applied by Babatunde et al. (2018) and Edike \& Babatunde (2017). The collected data was coded to obtain numeric values and then exported into IBM's Statistical Package of Social Sciences (SPSS) version 20.0. The descriptive statistical methods of the mean score and standard deviation were used to determine the SMPs used by contractors on construction job sites. The mean scores formed the basis for ranking the SMPs. Standard deviation was provided to rank SMPs with the same mean scores. In line with Babatunde et al. (2018), SMPs with lower standard deviation were ranked higher than SMPs with higher standard deviation. The decision rule regarding categorisation of SMPs about mean values were as follows: $\leq 1.00=$ never used, 1.01 to $2.00=$ rarely used, 2.01 to $3.00=$ sometimes used, 3.01 to $4.00=$ often used, and 4.01 to 5.00 = always used. Edike \& Babatunde (2017) used a slightly similar decision rule in their study of crime management on construction sites in Nigeria.

Cronbach's alpha was used to statistically determine the average interitem correlation of Likert scale items in a survey instrument. Cronbach's alpha model is one of the most popular internal consistency statistics used in research studies (Babatunde et al., 2018; Chileshe et al., 2020). The Cronbach's alpha values range from 0 to 1 , where 0 represents no reliability and 1 represents absolute reliability, respectively (Wuni et al., 2021). An alpha value greater than 0.70 is considered acceptable (OseiKyei \& Chan 2016). The Cronbach's alpha of 0.877 was obtained, which signifies an excellent internal consistency of the survey instrument adopted for this study. The result rendered the dataset reliable for further analysis. Further, out of 98 questionnaires distributed, 40 valid questionnaires were used, representing a $40.8 \%$ response rate. The survey's number of responses is considered satisfactory as it exceeds the 30-sample central limit theorem espoused in Wuni et al. (2021). Further, the 
response rate compares favourably against similar studies, targeting specific geospatial respondents such as $35 \%$, Lagos, Nigeria, (Farinloye et al., 2013), and 8.5\%, Southeastern, USA (Berg and Hinze, 2005).

\section{Results and Discussion}

\subsection{Profile of respondents}

The respondents' professional roles are considered a good representation of a diverse pool of experts and fields, with at least $60 \%$ being project managers and estimators (See Table 2). Fadiya et al. (2012) observed that directors and managers are decision makers who understand the consequences of theft and vandalism in the construction sector. Regarding working experience, $52.5 \%$ of the respondents had an accumulated working experience of more than 6 years while $47.5 \%$ had up to 5 years. The responses provided by the respondents could thus reflect primarily the contractors' theft and vandalism management strategies over the years.

Table 2: Respondents' professional roles

\begin{tabular}{lcc}
\hline Professional roles & Frequency & \% \\
\hline Company director & 4 & 10.0 \\
Estimators & 14 & 35.0 \\
Project manager & 10 & 25.0 \\
Site engineer & 1 & 2.5 \\
Purchasing coordinator & 1 & 2.5 \\
Site agent & 2 & 5.0 \\
Others & 8 & 20.0 \\
\hline
\end{tabular}

\subsection{Business characteristics of contractors}

The business characteristics of the responding contractors were also necessary for determining the credibility of the responses given to the questions about the contractors' SMPs. Regarding the age, $61.5 \%$ of the responding contractors have been in business for over 11 years (See Appendix 2), which is a good reflection of the contractor's theft and vandalism experiences across projects (Edike \& Babatunde 2017; Fadiya et al., 2012). Appendix 3 indicates that a considerably higher number of contractors $(60.0 \%)$ were licensed to operate in financial class 8 . This implies that a majority of contractors that took part in the survey operate in the unlimited category, indicating their involvement in mega projects where management of theft and vandalism is paramount. Usually, megaprojects entail deploying a substantial numeral of workers and plants (Fadiya et al., 2012). A combination of the building (95.0\%) and civil engineering $(60.0 \%)$ contractors responded to the questionnaire, thereby soliciting rich data from a homogenous population. Taken together, the information gathered from the contractors could be a true reflection of their SMPs.

\subsection{Contractors' management strategies for theft and vandalism}

The results for the mean score and ranking of SMPs are presented in appendix 4. Out of 44 SMPs, 11 SMPs, representing $25 \%$, fell within the "always used" category, 12 SMPs (27\%) in the 'often used' category, 15 SMPs $(34 \%)$ in the 'sometimes used' category and 6 SMPs $(14 \%)$ in the 'rarely used' category. None of the SMPs fell within the 'never used' category. The results and implications of these findings to the management of theft and vandalism are further discussed in descending order of their respective implementation categories. A table for each category, extracted from appendix 2, has been provided within the text to improve readability.

The high mean scores for SMPs in Table 3 indicate their 'always used' status on construction job sites. This finding aligns with a previous study by Edike and Babatunde (2017) which found an inventory of tools, materials and equipment, storing goods in the secured compound and marking of plant for identification, as the always used SMPs by contractors. Similarly, Farinloye et al. (2013) discovered that the most predominant preventative measures for theft of tools on construction sites were maintenance of tool inventory, secure storage and marking of tools. Similar findings were also reported by Berg and Hinze (2005). The study had found that contractors were more likely to use the maintenance of secure storage area $(71 \%)$, marking of tools $(67 \%)$ and maintenance of tool inventory $(61 \%)$ as measures for preventing theft on job sites. Equally, the use of guards, fencing, locking gates and marking of the plant were highly ranked SMPs on a study by Ablordeppey et al. (2020).

Table 3: Always used SMPs

\begin{tabular}{|c|c|c|c|c|}
\hline Security Management Practices & $\mathbf{N}$ & Mean & SD & Rank \\
\hline All Construction materials, tools and plants on site are inventoried & 40 & 4.55 & 0.71 & 1 \\
\hline Termination of employees caught stealing or committing vandalism & 40 & 4.48 & 0.99 & 2 \\
\hline Report theft and vandalism to the law enforcement agency & 40 & 4.45 & 0.99 & 3 \\
\hline Minimising the number of entrances & 40 & 4.38 & 0.93 & 4 \\
\hline Use of own-trained security personnel & 40 & 4.28 & 1.20 & 5 \\
\hline Use of Perimeter fences without barbed wire & 40 & 4.28 & 1.41 & 6 \\
\hline Assigned personnel with the responsibility of maintaining tight inventory & 40 & 4.23 & 1.21 & 7 \\
\hline Use of site cabins or containers for storing tools & 40 & 4.23 & 1.21 & 8 \\
\hline Use of padlocks and locked gates & 40 & 4.20 & 1.24 & 9 \\
\hline Removal of unused equipment from site & 40 & 4.13 & 1.07 & 10 \\
\hline The plant is covered with corporate logo or colours & 40 & 4.05 & 1.24 & 11 \\
\hline
\end{tabular}

The prevalence of SMPs in the 'always used' category can be attributed to the location of construction job sites. Incidents of crime are high on construction job sites in towns and cities because of high population growth and unemployment rates (Warne, 2016). The use of physical measures such as fences, storage areas, minimised and secured gates provide defence depth, especially for construction job sites located in highly populated areas 
such as CBDs. Physical security measures are employed to demarcate public and private land, prevent viewing of the site interior, restrict trespassing and prevent scaling the fencing (BSIA, 2012).

Besides, the SMPs in the 'always used' category may play a crucial role in repelling crimes committed by professional thieves. Even though professional thieves employ sophisticated means of committing a crime, using fences, guards, locked gates, and secure storage areas compromise the time efficiency in their criminal operations. While BSIA (2012) observes that delaying the action of a criminal increase the chances of their being caught, Edike and Babatunde (2017) assert that delaying tactics minimise the available time of the criminal for the targeted asset.

Further, evidence reveals that high crime incidents are reported to take place in the after-hours of weekdays and during weekends (Sakurai et al. 2008; Smith and Walmsley, 1999). Providing guardship services, securing storage areas and using padlocks and locked gates minimise crime on construction job sites during odd hours. Edike and Babatunde (2017) and Farinloye et al. (2013) stresses the importance of these SMPs in maintaining the security of construction assets.

Ordinarily, theft and vandalism on construction job sites have been attributed to the implementation of minimally inferior measures (Sakurai et al., 2008), most of which are SMPs in the 'always used' category. Berg and Hinze (2005) found that among the contractors that had used fencing, lockboxes, guards and removal of unused items as security measures, three contractors experienced more than 50 theft incidents and two contractors experienced 42 and 109 incidents of vandalism each. An average of 3.6 vandalism incidents was reported each year among the contractors. Regardless, implementation of SMPs in the 'always used' category remains common among contractors in the construction industry. Their high implementation cannot, therefore, be taken as a bureaucratic add-on without any additional value. Apart from lower cost, other invincible motivating factors such as the duty to fulfil legislative and administrative requirements seem to play a role.

Termination of employees caught stealing or committing vandalism (2nd, 4.48) is consistent with Section 59 of the Employment Act of Malawi of 2000. The Act stipulates that an employer is entitled to summarily dismiss an employee where an employee is guilty of serious misconduct inconsistent with the fulfilment of the expressed or implied conditions of his contract of employment (Malawi Government, 2000). According to BSIA (2012), employees have an implied obligation to keep the job sites secure, report crimes, and cooperate with the guard force. Employees who steal from job sites would be in contravention of this implied obligation, resulting in dismissal. In effect, Ebong (2017) highlights that the law has a deterrent effect. It functions through fear of being apprehended and punished to produce a desired sobering behaviour and repel thieves and vandals.

Further, Part III and V of the Malawi Occupational Health, Safety and Welfare Act of 1997 assign a legal duty on the employer to ensure the safety of his/her employees and the public at the workplace (Malawi Government,
1997). In fulfilling this duty, contractors erect fences and use locked gates to protect employees and the public from hazardous construction works. Contemporaneously, such measures provide a physical barrier and prevent unauthorised access to the Jobsite, especially by amateur opportunists. Again, terminating employment for offenders and reporting of crime to law enforcement agencies are enforced as administrative requirements. Employment for criminals would be terminated due to disciplinary action, which coincidentally would deter would-be offenders and set good precedence in the fight against crime. Conversely, reporting theft and vandalism incidents help contractors with information in applying internal disciplinary and recovery measures. Berg \& Hinze (2005) reported that $76 \%$ of contractors in the Southeastern United States frequently use the measure on construction job sites.

In terms of costs, the 'always used' SMPs are generally unsophisticated in their implementation. Ablordeppey et al. (2020) states that such SMPs entail less technology, making their costs relatively lower than technical systems. This study also conveys that perimeter fencing could be constructed from readily available reusable local materials such as timber, plywood, steel sheets and installed by simply nailing steel sheets or plywood to timber or steel poles. Further, steel containers (8th; 4.23) could be brought onto the job site in the early stages of the project to act as temporary storage areas and converted to any preferable use at the end of the project. Minimising the number of entry points (4th; 4.38) saves the cost incurred in installing the gates and maintenance of guardianship at access points. Likewise, the cost associated with using own-trained security personnel (5th; 4.28) could be relatively lower than hired police patrols (39th 2.03). These approaches achieve additional value without necessarily increasing the cost, thereby being prevalent among contractors.

An analysis of SMPs in the "often used" category (See Table 4) indicates that the measures are ordinarily used to supplement SMPs in the "always used" category. According to the Oxford dictionary, supplementary is defined as "provided in addition to something else in order to improve or complete it" (Oxford Learners Dictionary, 2020). Multiple examples are given to exemplify this assertion. Perimeter fences (6th, 4.28) could be toppled with ant-climb features (16th, 3.45) or used to display no trespassing signs (14th, 3.63); use of storage areas such as containers (8th, 4.23) could be enhanced by installing door and window protectors (13th, 3.63) (BSIA, 2012:1920); use of PIN and VIN (18th; 3.43) is critical in inventory management $(1 \mathrm{st} ; 4.55)$ while delaying delivery of whitegoods (15th; 3.53) minimises the number of unused items onsite (10th; 4.13). These synergies address the inadequacies inherent in the 'always used' SMPs and further explain their dominance among contractors.

Further, in instances where SMPs in the "always used" category are breached, SMPs in the "often used" category provides a security cover. This is achieved through sufficient delay to the action of the intruder caused by anti-climb features, use of protectors on doors and windows, use of padlocks, chains and wheel camps (19th; 3.43 ) and use of locks on oil and gas tanks (21st; 3.38). The complementarity makes these SMPs fall in the "often 
used" category and rank behind SMPs in the "always used" category. The deployment of SMPs in the 'often used' category could thus be a matter of choice and pick of measures that better supplement SMPs within the "always used" category on a particular construction job site.

Table 4: Often used SMPs

\begin{tabular}{|c|c|c|c|c|c|}
\hline Security Management Practices (SMPs) & $\mathbf{N}$ & Mean & SD & Rank & Category \\
\hline Station uniformed guards at entrance gates & 40 & 3.93 & 1.49 & 12 & \multirow{12}{*}{$\begin{array}{c}\text { Often } \\
\text { used }\end{array}$} \\
\hline Use of protectors for vulnerable doors and windows & 40 & 3.63 & 1.31 & 13 & \\
\hline Display of " No Trespassing " signs & 40 & 3.63 & 1.51 & 14 & \\
\hline Delaying delivery and installation of white goods & 40 & 3.53 & 1.28 & 15 & \\
\hline Use of perimeter fence with barbed wire & 40 & 3.45 & 1.55 & 16 & \\
\hline $\begin{array}{l}\text { Providing contact information for a responsible person during non- } \\
\text { working hours }\end{array}$ & 40 & 3.43 & 1.17 & 17 & \\
\hline $\begin{array}{l}\text { Recording of vehicle identification number (VIN) or a product } \\
\text { identification number (PIN) }\end{array}$ & 40 & 3.43 & 1.78 & 18 & \\
\hline $\begin{array}{l}\text { Secure small mobile equipment with padlocks, chains, hitches, wheel } \\
\text { clamps }\end{array}$ & 40 & 3.43 & 1.14 & 19 & \\
\hline Just-in-time delivery of materials and tools & 40 & 3.38 & 1.51 & 20 & \\
\hline Use locks on oil and gas tanks & 40 & 3.38 & 1.66 & 21 & \\
\hline Conduct staff security awareness training & 40 & 3.13 & 1.59 & 22 & \\
\hline $\begin{array}{l}\text { Tools such as hammers, shovels are marked with an indelible } \\
\text { identification mark }\end{array}$ & 40 & 3.05 & 1.50 & 23 & \\
\hline
\end{tabular}

The findings for the 'sometimes used' category indicates that the SMPs are mainly those used to prevent theft of plant stationed onsite (See Table 5). Such SMPs include the use of locking points to immobilise plant (24th; 2.93), strategic parking for large equipment (26th; 2.83 ), engraving equipment with serial numbers (27th; $2.78)$, installing plant tracking devices $(34 ; 2.38)$ and disabling plant with hidden ignition cut-out switch (37th; 2.18). Berg \& Hinze (2005) reported that $67 \%$ of contractors parked equipment in well-lighted areas, $43 \%$ parked equipment in a specific formation, $42 \%$ used strategic parking of equipment, and $37 \%$ included additional identification marks on the plant. Similar findings were also reported by Edike and Babatunde (2017) and Farinloye (2012). Therefore, the prevalence of SMPs in the 'sometimes used' category across studies as measures for securing construction plant entails their effectiveness in preventing theft of machinery. However, large contractors that participated in this study do not use these SMPs frequently. A plausible explanation for the observation could be that such contractors rely on 'always' and 'often' used SMPs to mitigate plant theft.

Again, pre-screening of applicants (35th, 2.35) and employee hotline (38th, 2.05) are not widely adopted, inconsistent with findings of Edike \& Babatunde (2017: 40, 45). Pre-screening of applicants ensures that only those individuals without criminal records are employed. Similarly, establishing an employee hotline to report crimes ensures that incidents of theft and vandalism, planned or abrupt, are instantaneously reported for immediate action. According to Sharma and Bausma (2009), these SMPs minimise incidents of theft on construction job sites. It would be therefore prudent for contractors to adopt these practices if their effectiveness is anything to consider.

Table 5: Sometimes used SMPs

\begin{tabular}{|c|c|c|c|c|c|}
\hline Security Management Practices (SMPs) & $\mathbf{N}$ & Mean & SD & Rank & Category \\
\hline Using locking points to immobilise plant when not in use & 40 & 2.93 & 1.38 & 24 & \\
\hline Security planning and design & 40 & 2.90 & 1.37 & 25 & \\
\hline Strategic parking for large equipment & 40 & 2.83 & 1.56 & 26 & \\
\hline Engraving the equipment with serial numbers & 40 & 2.78 & 1.40 & 27 & \\
\hline Use of lockable steel vaults for storing tools and small equipment & 40 & 2.70 & 1.34 & 28 & \\
\hline Encouraging employees to mark ID numbers on tools & 40 & 2.68 & 1.44 & 29 & \\
\hline Crime prevention coordinator & 40 & 2.60 & 1.63 & 30 & \\
\hline Computer-based documentation of information onsite & 40 & 2.62 & 1.52 & 31 & Sometimes \\
\hline Use of full-height turnstile on entrances & 40 & 2.54 & 1.35 & 32 & used \\
\hline Use of workers badge or ID & 40 & 2.43 & 1.38 & 33 & \\
\hline Install tracking devices on the plant or equipment & 40 & 2.38 & 1.41 & 34 & \\
\hline $\begin{array}{l}\text { Pre-employment screening investigation to verify applicants' criminal } \\
\text { history }\end{array}$ & 40 & 2.35 & 1.46 & 35 & \\
\hline Use of guard dogs after working Hours & 40 & 2.28 & 1.52 & 36 & \\
\hline Disabling machines with hidden ignition cut-out switch & 40 & 2.18 & 1.22 & 37 & \\
\hline Establishing an employee hotline to report crime & 40 & 2.05 & 1.30 & 38 & \\
\hline
\end{tabular}


Table 6 shows that 6 SMPs, representing 14\%, fell within the "rarely used" category. They are least ranked, 39 th to 44th, with mean scores ranging from 2.03 to 1.50 . This finding is consistent with Edike and Babatunde's (2017) study, which discovered the least use of CCTV and alarm systems (30th, 1.33) among contractors in Nigeria. Security cameras and alarm systems were also minimally ranked in a study of theft on construction job sites in the Upper West Region of Ghana (Ablordeppey et al., 2020). Their unpopularity has been attributed to the high cost of procurement, installation and operation. Their none deployment ought to be predominant among small and medium contractors and not among large contractors.
Here again, the domineering and adamantine effect of SMPs in the 'always' and 'often' used categories seem to be in manifestation. However, considering that none use of technical systems is a major cause of crime on job sites (Berg and Hinze, 2005) and that the security risk is high on large projects, deployment of technical systems as deterrence and detection security strategy needs to be encouraged among large contractors. The cost-benefit analysis for the deployment of these SMPs is sufficiently compelling for large contractors. The systems are reusable and may offer additional value, such as monitoring health and safety issues.

Table 6. Rarely used SMPs

\begin{tabular}{|c|c|c|c|c|c|}
\hline Security Management Practices (SMPs) & $\mathbf{N}$ & Mean & SD & Rank & Category \\
\hline Use of police patrols & 40 & 2.03 & 1.23 & 39 & \multirow{6}{*}{ Rarely used } \\
\hline Use of neighbourhood watch & 40 & 2.00 & 1.30 & 40 & \\
\hline Fitting Passive electronic tags or markers to plant & 40 & 1.85 & 1.19 & 41 & \\
\hline Use alarm system to detect motion and send signals & 40 & 1.53 & 1.11 & 42 & \\
\hline Use of electronic entrance system & 40 & 1.50 & 1.26 & 43 & \\
\hline Use of CCTV/security cameras & 40 & 1.48 & 1.11 & 44 & \\
\hline
\end{tabular}

\section{Conclusion}

Crime prevention has become a major concern in the construction industry due to theft and vandalism costs. This paper explored SMPs implemented by contractors in curbing theft and vandalism on construction job sites in the Southern Region of Malawi. SMPs that were commonly implemented included 11 in the 'always used' and 12 in the 'often used' categories. The ubiquitous nature of SMPs in these two categories is attributed to the job sites' locations that demand the implementation of physical measures. Other factors that influence these SMPs include compliance with legislative and administrative requirements and a strong synergism among the SMPs. It was expected that large contractors would implement the proven to be successful security measures to mitigate threats on their job sites. This would be due to the high value of construction assets found on such job sites. However, it was surprising to note that most SMPs used to prevent theft of plants and tools were categorised as 'sometimes used'. Similarly, technical systems such as CCTV and alarm systems, together with background checks on employees and establishing employee hotline, were among the least used SMPs. Therefore, the absence of these SMPs is an indicator of how exposed job sites of large contractors are to theft and vandalism. This would also imply that cost is not the only most influencing factor in choosing security measures for contractors. If that were the case, the implementation of the technical systems would have been high among the large contractors probed in this study, whose financial capacity is an enabler to investment in such systems. Instead, other compelling factors such as legislative and administrative requirements play a role.

\section{References}

Ablordeppey, E.E, Moo, F., Akorsu, W. and Mustapha, A. (2021). Minimising Theft on Construction
Together, contractors should prioritise the implementation of SMPs in the 'always used' category while the deployment of SMPs in another category should be in tandem with the overall security assessment of the construction job site. For example, SMPs, in the "often used" category should be employed to supplement inadequacies created by "always used" SMPs, while SMPs in the "sometimes used" category should be employed to deter theft of tools and plants. SMPs in the "rarely used" categories are the most effective anti-theft and anti-vandalism SMPs. Large contractors should therefore reconsider investing in technical systems.

The findings contribute to the wider construction project management discourse where issues of theft and vandalism are paramount. The results provide empirical evidence on SMPs that need improvement to prevent theft and vandalism on job sites. Further, the study contributes to the theft and vandalism phenomenon by suggesting that implementing SMPs belonging to a particular category only may not necessarily result in improved security on construction job sites. Implementation of a combination of SMPs based on security risk assessment may be necessary to achieve a desired level of security. However, though adequate, the study is limited by a relatively smaller sample size which may compromise the generalizability of the results. Therefore, this study might have offered a generic analysis on which future research studies covering wide geospatial areas may be based. Future research may also consider conducting discriminant analysis of the results using ANOVA or ttest to investigate if the implementation of SMPs varies with business characteristics.

Sites in Ghana: The Perspective of Contractors in the Upper West Region of Ghana. Civil and Engineering Research, 12, (5), 30-40. 
Allianz, (2018). 2018 will hit a new high for plant theft claims. Retrieved from https://www.allianz.co.uk/newsand-insight/news-blogs-and-press-

releases/2018/11/2018-predicted-new-high-for-plant-

theft-claims.html

Babatunde, S.O., Perera, S. and Adeniyi, O. (2018). Identification of critical risk factors in public-private partnership project phase in developing countries. Benchmarking: An International Journal, 26, (2), 334355 .

Berg, R. and Hinze, J. (2005). Theft and vandalism on construction sites. Journal of Construction Engineering and Management, 131, (7), 826-833.

Big Box. (2018). Preventing construction site theft in South Africa. Retrieved from https://www.bigboxcontainers.co.za/blog/preventingconstruction-site-theft-south-africa

Boba, R. and Santos, R. 2006. Burglary at singlefamily house construction sites. Working paper [43], Office of Community Oriented Policing Services, US Department of Justice, Washington. Retrieved from https://justiceacademy.org/iShare/Library-

Training/e07021611.pdf

British Security Industry Association (BSIA). (2012). Construction site security-a guide. Working paper [123], British Security Industry Association, January, UK. Retrieved from https://www.bsia.co.uk/zappfiles/bsiafront/new\%20pdfs/123-construction-site-security-aguide.pdf

Chileshe, N. Njau, C.W., Kabichii, B.K., Macharia, L.N. and Kavishe, N. (2020). Critical success factors for public-private partnerships (PPP) infrastructure and housing projects in Kenya. International Journal of Construction Management, 1-23.

Chyung, S.Y., Roberts, K., Swanson, L. and Hankinson, A. (2017). Evidence-based Survey Design: The Use of a Midpoint on the Likert Scale. International Science for Performance, 56, (10), 15-23.

Danku, J.C. (2020). Exploring the Concept of Social Licence in the Construction Industry of a Developing Country. Journal of Construction Business and Management, 4, (2), 25-33.

Ebong, S. (2017). Influencing behavior for crime prevention through architectural design and construction: an overview. Journal of Sustainable Architectural and Civil Engineering, 2, (19), 5-12.

Edike, U.E. and Babatunde, A. (2017). Crime prevention on construction site: A study of Ogun State, Nigeria. Covenant Journal of Research in the Built Environment, 5, (1), 32-47.

Fadiya, O.O., Georgakis, P., Chinyio, E. and Nwagboso, C. (2012). Perceptions of Building Contractors Concerning Plant Theft. International Journal of Architecture, Engineering and Construction, 1, (1), 47-54.

Farinloye, O., Odusani, K. and Adewunmi, Y. (2013). Theft and vandalism control measures on building sites in Lagos, Nigeria. Journal of Engineering, Project and Production Management, 3, (1), 9-21.

Gwynn, M., Engels, F., Green, N., Henry, J., Kellow, J. (2005) Theft of Construction Plant and Equipment. International Association of Engineering Insurers (IMIA)
43 (05). Retrieved from https://www.imia.com/wpcontent/uploads/2013/05/wgp4305.pdf

Iwuagwu, C. (2014). Statistical appraisal of crime rate in Nigeria. Journal of Physical Science and Innovation, 6, (1), 38-48.

Malawi Government. (1997). Occupational safety, health and welfare. Retrieved from https://www.malawi.gov.mw/labour/doc/occ\%20safety\% 20health.pdf

Malawi Government. (2000). Employment Act 2000 No. 6 of 2000. Retrieved from https://www.ilo.org/wcmsp5/groups/public/--ed_protect/---protrav/---

ilo_aids/documents/legaldocument/wcms_125534.pdf

Montealegre, F. (2003). Jobsite security in residential construction. Retrieved from https://ufdc.ufl.edu/UFE0001192/00001/pdf

National Construction Industry Council (NCIC). (2019). First and upgrading registration form for building and civil - 2019. Retrieved from https://ncic.mw/resources/

Nyakala, K.S., Pretorius, J.C. and Vermeulen, A. (2021). Construction quality process implementation as a source of competitive advantage in small and mediumsized construction projects. Journal of Construction Business and Management, 4, (2), 46-54.

Osei-Kyei, R. and Chan, A.P.C. (2016). Factors attracting private sector investments in public-private partnerships in developing countries: A survey of international experts. Journal of financial management of property and construction, 22, (1), pp. 92-111.

Oxford Learners Dictionary. (2020). Supplementary. Retrieved from https://www.oxfordlearnersdictionaries.com/definition/e nglish/supplementary?q=supplementary

Rahman, M.M, Yap, Y.H., Ramli, N.R., Dullah, M.A. and Shamsuddin, M.S.W. (2017). Causes of Shortage and Delay in Material Supply: A Preliminary Study. IOP Conf. Series: Materials Science and Engineering. 1-7

Rowley, J. (2012). Conducting research interviews. Management Research Review, 35, (3/4), 260-271.

Sakurai, Y., Mayhew, P. and White, M. (2008). Theft and vandalism at residential building sites in Australia. Retrieved from http://www.sanantonio.gov/saPD/p df/CONSTRUCTION_SITE.pdf

Sharma, A. and Bausman, D. (2009). Construction site security - the impact of company size and loss history on security measures. Retrieved from http://ascpro0.ascweb.org/archives/cd/2010/paper/CPRT 119002010.pdf

Smith, A. and Walmsley, R. (1999). The nature and extent of construction plant theft. Working paper [117], Home Office, London. Retrieved from https://www.imia.com/wp-

content/uploads/2013/05/EP44-2010-Plant-TheftReport-UK-vers-4.pdf.

The People's Law Dictionary. (1981-2005) Theft. Retrieved from https://legaldictionary.thefreedictionary.com/theft

Warne, L. (2016). Crime in the construction industry. Retrieved from https://prime-secure.co.uk/wpcontent/uploads/2021/02/CIOB-Crime-in-theConstruction-Industry.pdf 
Wuni, I.Y., Shen, G.Q. and Osei-Kyei, R. (2021). Evaluating the critical success criteria for prefabricated prefinished volumetric construction projects. Journal of Financial Management of Property and Construction,
Vol. ahead-of-print No. ahead-of-print. Retrieved from https://doi-org.gcu.idm.oclc.org/10.1108/JFMPC03-2020-0013.

Appendix 1: Proposed construction Jobsite security management strategies

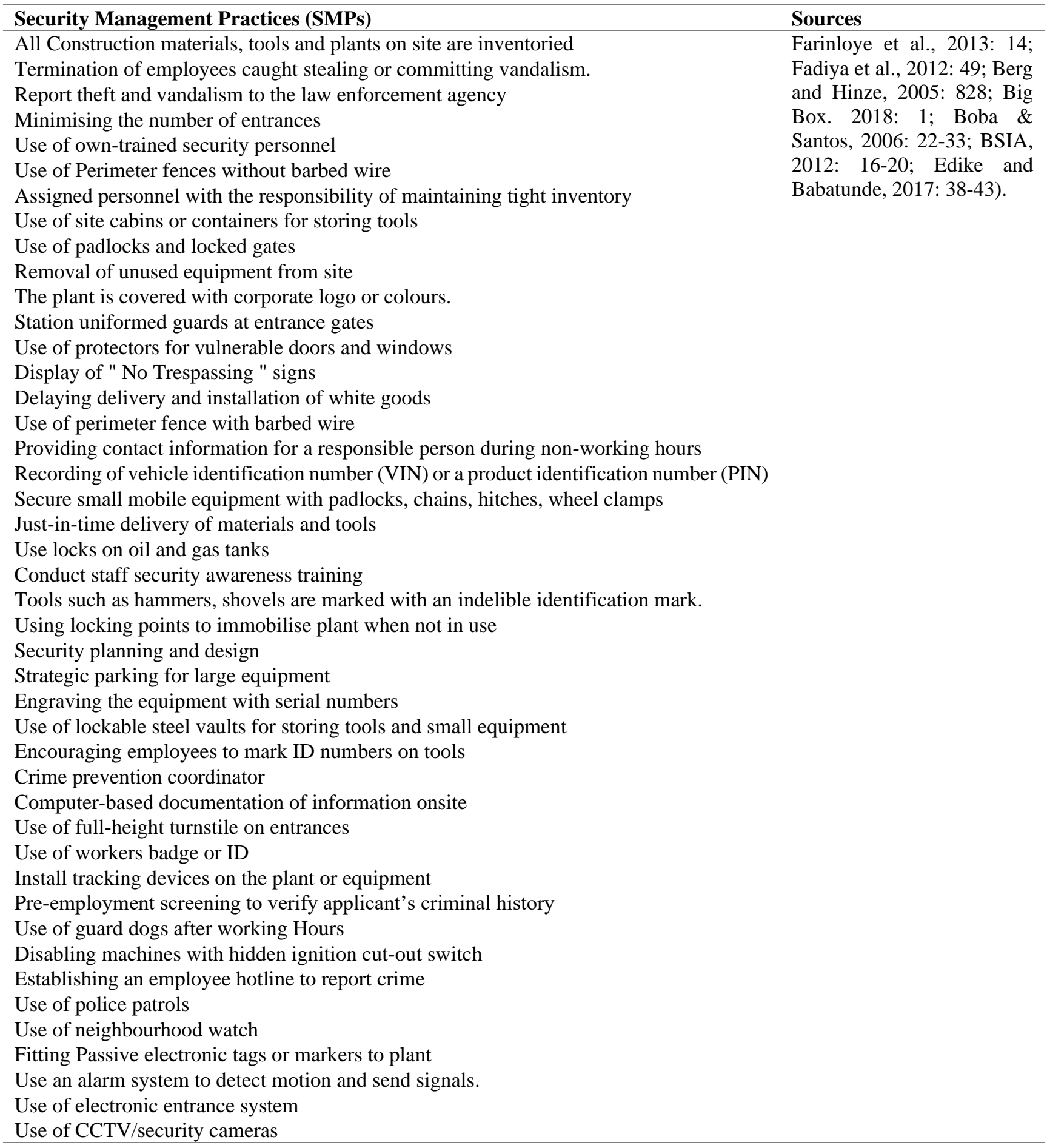




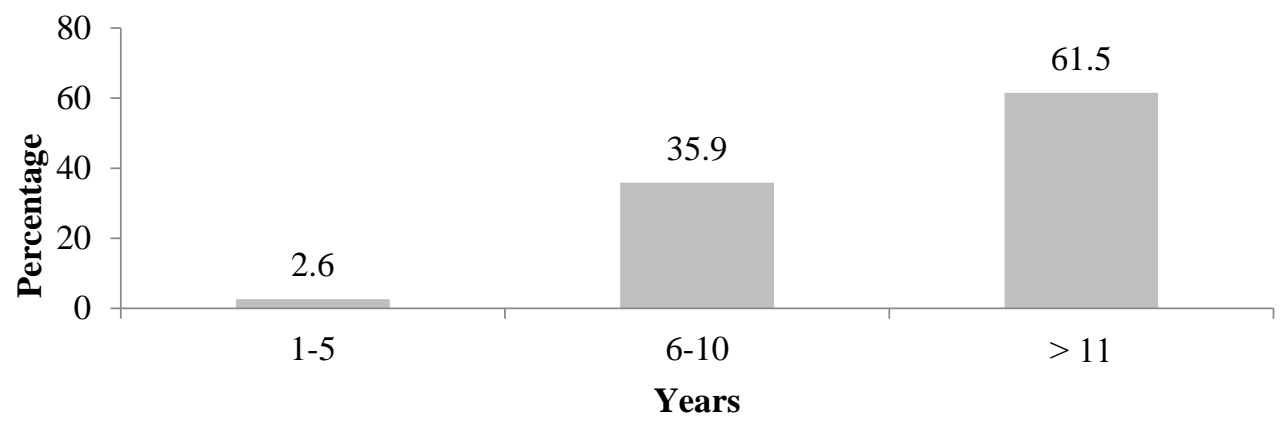

Appendix 3: Business financial class of registration

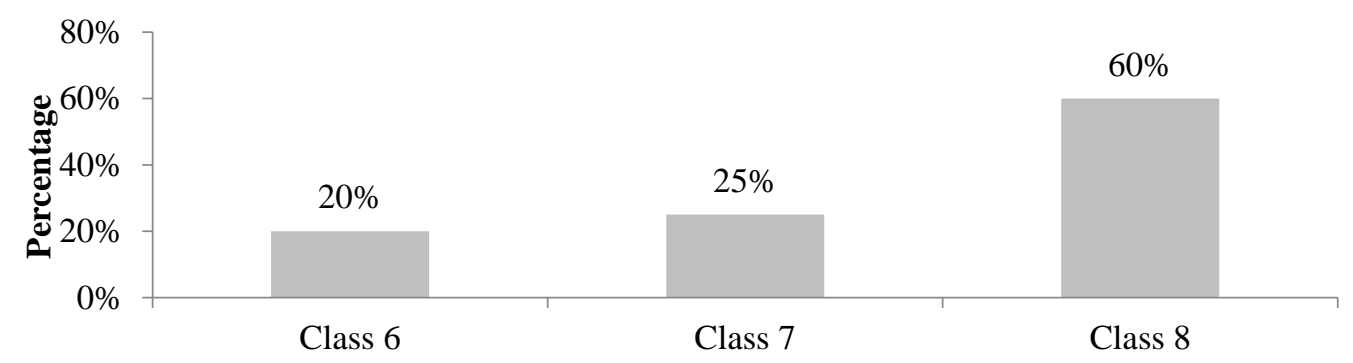

Appendix 4: Implementation of SMPs by contractors

\begin{tabular}{|c|c|c|c|c|c|}
\hline Security Management Practices (SMPs) & $\mathbf{N}$ & Mean & SD & Rank & Category \\
\hline All Construction materials, tools and plants on site are inventoried & 40 & 4.55 & 0.71 & 1 & \multirow{11}{*}{$\begin{array}{l}\text { Always } \\
\text { used }\end{array}$} \\
\hline Termination of employees caught stealing or committing vandalism & 40 & 4.48 & 0.99 & 2 & \\
\hline Report theft and vandalism to the law enforcement agency & 40 & 4.45 & 0.99 & 3 & \\
\hline Minimising the number of entrances & 40 & 4.38 & 0.93 & 4 & \\
\hline Use of own-trained security personnel & 40 & 4.28 & 1.20 & 5 & \\
\hline Use of Perimeter fences without barbed wire & 40 & 4.28 & 1.41 & 6 & \\
\hline Assigned personnel with the responsibility of maintaining tight inventory & 40 & 4.23 & 1.21 & 7 & \\
\hline Use of site cabins or containers for storing tools & 40 & 4.23 & 1.21 & 8 & \\
\hline Use of padlocks and locked gates & 40 & 4.20 & 1.24 & 9 & \\
\hline Removal of unused equipment from site & 40 & 4.13 & 1.07 & 10 & \\
\hline The plant is embroiled with corporate logo or colours & 40 & 4.05 & 1.24 & 11 & \\
\hline Station uniformed guards at entrance gates & 40 & 3.93 & 1.49 & 12 & \multirow{12}{*}{ Often used } \\
\hline Use of protectors for vulnerable doors and windows & 40 & 3.63 & 1.31 & 13 & \\
\hline Display of " No Trespassing " signs & 40 & 3.63 & 1.51 & 14 & \\
\hline Delaying delivery and installation of white goods & 40 & 3.53 & 1.28 & 15 & \\
\hline Use of perimeter fence with barbed wire & 40 & 3.45 & 1.55 & 16 & \\
\hline $\begin{array}{l}\text { Providing contact information for a responsible person during non- } \\
\text { working hours }\end{array}$ & 40 & 3.43 & 1.17 & 17 & \\
\hline $\begin{array}{l}\text { Recording of vehicle identification number (VIN) or a product } \\
\text { identification number (PIN) }\end{array}$ & 40 & 3.43 & 1.78 & 18 & \\
\hline $\begin{array}{l}\text { Secure small mobile equipment with padlocks, chains, hitches, wheel } \\
\text { clamps }\end{array}$ & 40 & 3.43 & 1.14 & 19 & \\
\hline Just-in-time delivery of materials and tools & 40 & 3.38 & 1.51 & 20 & \\
\hline Use locks on oil and gas tanks & 40 & 3.38 & 1.66 & 21 & \\
\hline Conduct staff security awareness training & 40 & 3.13 & 1.59 & 22 & \\
\hline $\begin{array}{l}\text { Tools such as hammers, shovels are marked with an indelible } \\
\text { identification mark }\end{array}$ & 40 & 3.05 & 1.50 & 23 & \\
\hline Using locking points to immobilise plant when not in use & 40 & 2.93 & 1.38 & 24 & \multirow{10}{*}{$\begin{array}{l}\text { Sometimes } \\
\quad \text { used }\end{array}$} \\
\hline Security planning and design & 40 & 2.90 & 1.37 & 25 & \\
\hline Strategic parking for large equipment & 40 & 2.83 & 1.56 & 26 & \\
\hline Engraving the equipment with serial numbers & 40 & 2.78 & 1.40 & 27 & \\
\hline Use of lockable steel vaults for storing tools and small equipment & 40 & 2.70 & 1.34 & 28 & \\
\hline Encouraging employees to mark ID numbers on tools & 40 & 2.68 & 1.44 & 29 & \\
\hline Crime prevention coordinator & 40 & 2.60 & 1.63 & 30 & \\
\hline Computer-based documentation of information onsite & 40 & 2.62 & 1.52 & 31 & \\
\hline Use of full-height turnstile on entrances & 40 & 2.54 & 1.35 & 32 & \\
\hline Use of workers badge or ID & 40 & 2.43 & 1.38 & 33 & \\
\hline
\end{tabular}




\begin{tabular}{llllll}
\hline Install tracking devices on the plant or equipment & 40 & 2.38 & 1.41 & 34 & \\
Pre-employment screening investigation to verify applicant's criminal & 40 & 2.35 & 1.46 & 35 & \\
history & & & & & \\
Use of guard dogs after working Hours & 40 & 2.28 & 1.52 & 36 & \\
Disabling machines with hidden ignition cut-out switch & 40 & 2.18 & 1.22 & 37 & \\
Establishing an employee hotline to report crime & 40 & 2.05 & 1.30 & 38 & \\
\hline Use of police patrols & 40 & 2.03 & 1.23 & 39 & \\
Use of neighbourhood watch & 40 & 2.00 & 1.30 & 40 & \\
Fitting Passive electronic tags or markers to plant & 40 & 1.85 & 1.19 & 41 & Rarely used \\
Use alarm system to detect motion and send signals & 40 & 1.53 & 1.11 & 42 & \\
Use of electronic entrance system & 40 & 1.50 & 1.26 & 43 & \\
Use of CCTV/security cameras & 40 & 1.48 & 1.11 & 44 & \\
\hline
\end{tabular}

